\title{
Performance evaluation of nano-silica concrete
}

\author{
Kakara $S$ J Kumar ${ }^{1}, M V$ Seshagiri Rao $^{2}, V$ Srinivasa Reddy $^{3}, S$ Shrihari ${ }^{4}$ \\ ${ }^{1}$ Research Scholar of Civil Engineering, JNTUH CEH, Hyderabad. \\ ${ }^{2}$ Ex-Professor, JNTUH CEH and Professor, CVR College of Engineering, Hyderabad \\ ${ }^{3}$ Professor, Department of Civil Engineering, GRIET, Hyderabad. Email id: vempada@gmail.com \\ ${ }^{4}$ Professor, Department of Civil Engineering, VJIT, Hyderabad.
}

\begin{abstract}
In this paper, the study of the influence of nano-silica (nano- $\left.\mathrm{SiO}_{2}\right)$ on the properties of the interface between CSH gel and cement particles and its effect on nano-mechanical properties of the products at the interface zone was examined. In this paper M50 grade SCC mixes were developed using $5 \%$ micro-silica and various percentages of $0.5 \%, 1.0 \%$ and $1.5 \%$ nano- $\mathrm{SiO}_{2}$. For $1.0 \%$ nano- $\mathrm{SiO}_{2}$ addition to M50 grade SCC mix, the compressive strength is maximum. Similarly concrete quality using non-destructive techniques, water absorbtion capacity and porosity are also assessed.
\end{abstract}

\section{Introduction}

Concrete is a composite material consisting of many phases in micro and macro scale level. It is strong due to the heterogeneous nature acquired due to (1) interfacial transition zone between aggregate and matrix, (2) interaction between sand and paste matrix and (3) collaboration among CSH gel, large crystals of $\mathrm{Ca}(\mathrm{OH})_{2}$ , unhydrated cement particles and pores formed due to high $\mathrm{w} / \mathrm{c}$ ratio. Interface between coarse aggregate, fine aggregate and cement paste is understood well with micro observational studies but the phase between the unhydrated cement grains and CSH gel was not been explored effectively especially in concretes with high $\mathrm{w} / \mathrm{c}$ ratio due to availability of high amount of unhydrated cement particles. To enable a uniform distribution of nano- $\mathrm{SiO}_{2}$ in paste, colloidal nano- $\mathrm{SiO}_{2}$ (CNS) was used instead of nano- $\mathrm{SiO}_{2}$ powder. $\mathrm{The} \mathrm{SiO}_{2}$ content of CNS was larger than $99 \%$ by weight, and the $\mathrm{pH}$ value was 11 .

\section{Micro-silica and Nano-silica}

Nanosilica demonstration that presence of nanoparticles in cement increases the CSH gel chain length thereby increasing the stiffness of CSH. This highly stiff $\mathrm{CSH}$ prevents calcium leaching mechanism improving the durability of concrete.
Micro-silica and nano-silica conforms to IS 15388:2003. Micro-silica and nano-silica falls under category of Silica fume. The tables below physical and chemical properties of micro-silica and nano-silica. Silica fume is available in the form of micro-silica and nano-silica. Micro-silica is about 100 times smaller than cement size whereas nano-silica is about 1000 times smaller than cement.

Table 1. Physical Characteristics of Colloidal Nanosilica

\begin{tabular}{|c|c|}
\hline \multicolumn{1}{|c|}{ Property } & Value \\
\hline $\begin{array}{c}\text { Average Particle } \\
\text { size }(\mathrm{nm})\end{array}$ & 21 \\
\hline Density $(\mathrm{g} / \mathrm{cm} 3)$ & 2.3 \\
\hline Molar Mass $(\mathrm{g} / \mathrm{mol})$ & 59.30 \\
\hline Melting Point $\left({ }^{\circ} \mathrm{c}\right)$ & 1620 \\
\hline Boiling Point $\left({ }^{\circ} \mathrm{c}\right)$ & 2325 \\
\hline Specific gravity $(\mathrm{g} / \mathrm{cm} 3)$ & 1.11 \\
\hline Specific Surface $(\mathrm{m} 2 / \mathrm{g})$ & 139 \\
\hline $\begin{array}{l}\text { Active nano silica } \\
\text { content }\end{array}$ & $35-40 \%$ \\
\hline pH & $9.3-9.6$ \\
\hline Texture & Milky White Liquid \\
\hline
\end{tabular}


Table 2. Chemical Composition of Nanosilica

\begin{tabular}{|c|c|c|c|c|c|c|c|c|}
\hline Oxides & $\mathrm{SiO} 2$ & $\mathrm{C}$ & $\mathrm{MgO}$ & $\mathrm{CaO}$ & $\mathrm{Al} 2 \mathrm{O} 3$ & $\mathrm{FeO}$ & $\mathrm{TiO} 2$ & L.O.I \\
\hline \% by Weight & 99.90 & - & - & - & - & - & - & 2.9 \\
\hline
\end{tabular}

Table 3. Physical properties of Microsilica

\begin{tabular}{|c|c|c|c|}
\hline S.No & Property & Limits & Value \\
\hline 1 & $>45$ micron & $\begin{array}{c}\text { Maximum } \\
10 \%\end{array}$ & 0.55 \\
& & $\begin{array}{c}\text { Minimum } \\
105 \%\end{array}$ & 134 \\
\hline 2 & $\begin{array}{c}\text { Pozzolanic } \\
\text { Activity Index }\end{array}$ & $\begin{array}{c}\text { Min. } 15 \mathrm{~m} 2 / \mathrm{g} \\
500-700 \\
\mathrm{~kg} / \mathrm{m} 3\end{array}$ & 630 \\
\hline 4 & Sp. Surface & 630 \\
& Bulk Density & \multicolumn{2}{|c}{} \\
\hline
\end{tabular}

Table 4. Chemical properties of Microsilica

\begin{tabular}{|c|c|c|c|}
\hline S.No & Property & Limits & Value \\
\hline 1 & SiO2 & Min.85.0\% & 90.5 \\
\hline 2 & Moisture Content & Max.3.0\% & 0.63 \\
\hline 3 & Loss of Ignition & Max.6.0\% & 1.24 \\
\hline
\end{tabular}

Micro-silica mainly acts as a filler densely packing the voids created by the CSH gel and un-hydrated cement particles. Due to the presence of high reactive silica in micro-silica which reacts with calcium hydroxide to form additional hydrates which adds to the strength and stiffness of the concrete. Nano-silica has higher pozzolanic reactivity than micro-silica and also helps in lowering the water demand and reduces the capillary pores due to improved particle packing and developed intermolecular forces which may make concrete little stiff to work with. Due to addition of micro-silica there is decrease in setting times of the cement paste this reduction is observed more when nano-silica is used.

The objective of the present work is to evaluate performance of nano-silica in self-compacting concrete (SCC) of M50 grade. Nan Su mix design principles are adopted to arrive at the quantities required for M50 grade SCC.

\section{Effect of dosage of nano-SiO 2}

To quantify the amount of nano- $\mathrm{SiO}_{2}$ to be used in concrete, it is admixed with cement mortar cubes and tested for compressive strength. The amount of Nano$\mathrm{SiO}_{2}$ added are $0.5 \%, 1.0 \%$ and $1.5 \%$ by weight of the cement.

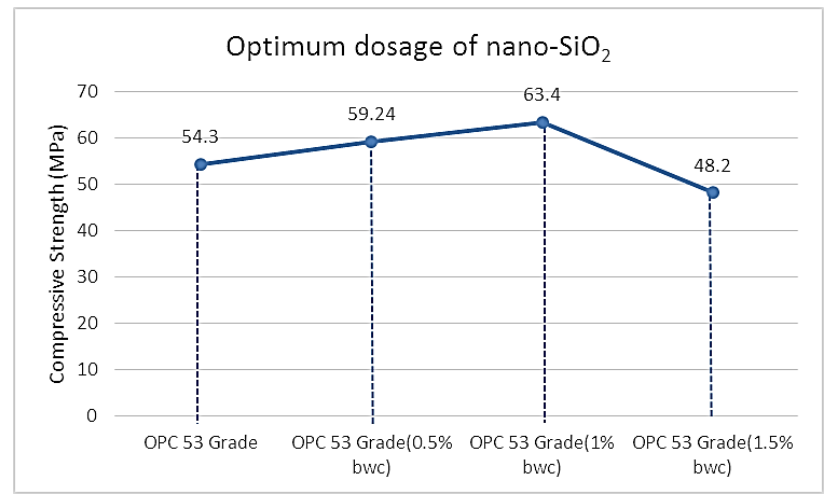

Fig. 1. Optimum dosage of nano- $\mathrm{SiO}_{2}$

For $1 \%$ addition of nano- $\mathrm{SiO}_{2}$ by weight of cement, the strengths obtained in cement mortar cubes is maximum so for further examinations this is considered as the optimum percentage of nano- $\mathrm{SiO}_{2}$ is adopted.

\section{Effect of nano-SiO ${ }_{2}$ on setting times}

Table below presents the effect of nano- $\mathrm{SiO}_{2}$ on setting times of cement mortars. With the addition of nano- $\mathrm{SiO}_{2}$ to the cement decreases the setting times.

\section{Consistency}

A flow table test was conducted as per IS 5512-1983 to determine the flow for the nano- $\mathrm{SiO}_{2}$ admixed mortars.

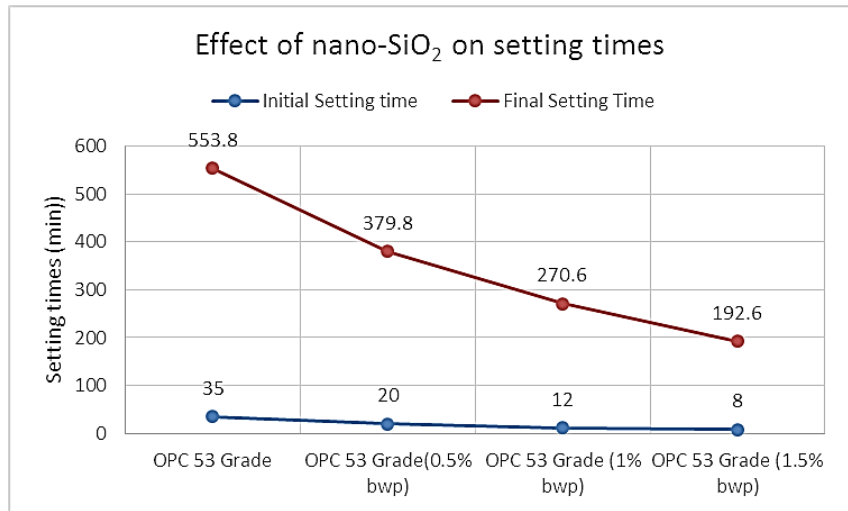

Fig. 2. Effect of nano- $\mathrm{SiO}_{2}$ on setting times 


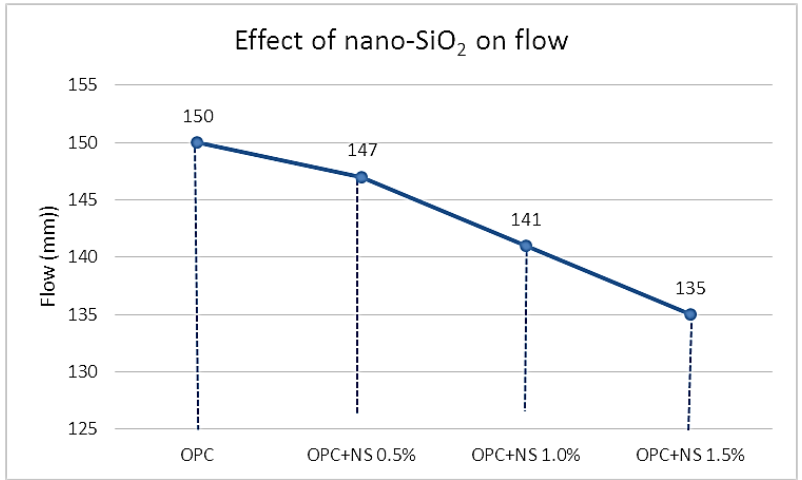

\section{Mix quantities}

Super plasticizers and mix quantities are revised subjected to satisfaction of flow properties as per
Fig. 3. Effect of nano- $\mathrm{SiO}_{2}$ on flow

As the percentage of nano- $\mathrm{SiO}_{2}$ was increased in mortar specimens there is a gradual increase in consistency was noted due to improved homogeneity of the cement matrix in nano- $\mathrm{SiO}_{2}$ admixed cementitous materials. The initial setting time of nano- $\mathrm{SiO}_{2}$ mixed samples drastically decreased due to the ultra-fine size of nano silica particles.

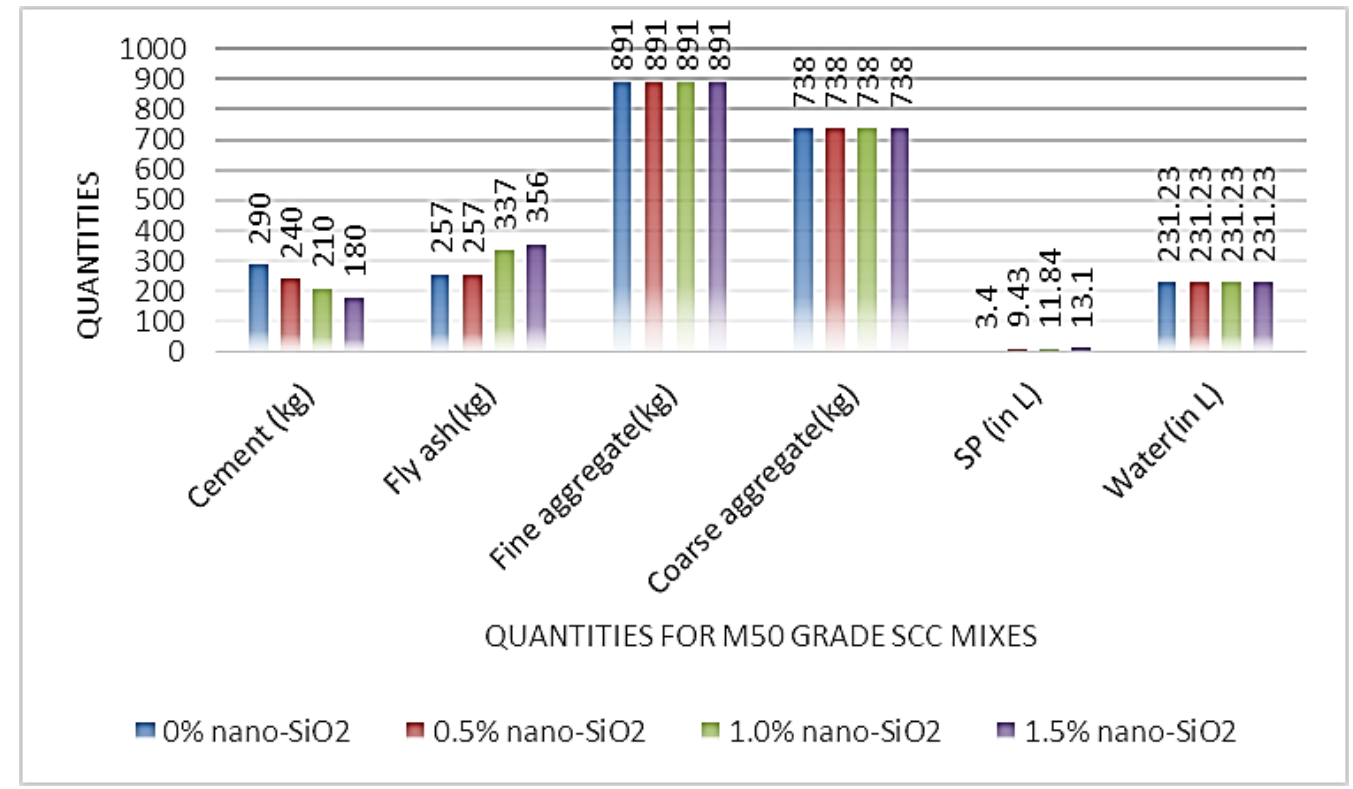

Fig. 4. Effect of nano- $\mathrm{SiO}_{2}$ on flow consistency

\section{Fresh properties on SCC as per \\ EFNARC guidelines}

EFNARC Guidelines. 5\% Microsilica is added to attain the desired compressive strength.

Based on the Nan-Su mix design the quantities that are obtained for M50 grade is listed below:

The following table presents the various workability tests based on EFNARC guidelines

Table 5. Fresh properties on SCC as per EFNARC guidelines

\begin{tabular}{ccccc} 
Workability Tests & $0 \% \mathrm{Nano}-\mathrm{SiO}_{2}$ & $0.5 \% \mathrm{Nano}-\mathrm{SiO}_{2}$ & $1.0 \% \mathrm{Nano}-\mathrm{SiO}_{2}$ & $1.5 \% \mathrm{Nano}_{-} \mathrm{SiO}_{2}$ \\
\hline Slump flow $(\mathrm{mm})$ & 635 & 657 & 653 & 630 \\
$\mathrm{~J}$ ring $(\mathrm{mm})$ & 3.1 & 5.2 & 5.3 & 4.2 \\
V funnel $(\mathrm{Sec})$ & 8.3 & 11 & 9 & 5.3 \\
L box & 0.98 & 0.82 & 0.82 & 0.81
\end{tabular}

\section{Compressive strengths of nano- $\mathrm{SiO}_{2}$ SCC mixes}

The following table presents the compressive strengths of nano- $\mathrm{SiO}_{2} \mathrm{SCC}$ mixes mixed with various dosages of nano-silica. Compressive strength found to be more for $1.0 \%$ addition of nano- $\mathrm{SiO}_{2}$. The percentage of nano silica is restricted to $1 \%$ due to workability issues. This seems to be controlled by the particle size distribution 
and the high specific surface area of nano- $\mathrm{SiO}_{2}$ in the presence of poly-carboxylate (PCE based) superplasticizer. With a further increase in nano- $\mathrm{SiO}_{2}$ content, the pozzolanic reaction and the resulting hydrated products formation increases, but along also increases the micro-cracking caused by the selfdesiccation effect, resulting in harmfully disturbing its strength development.

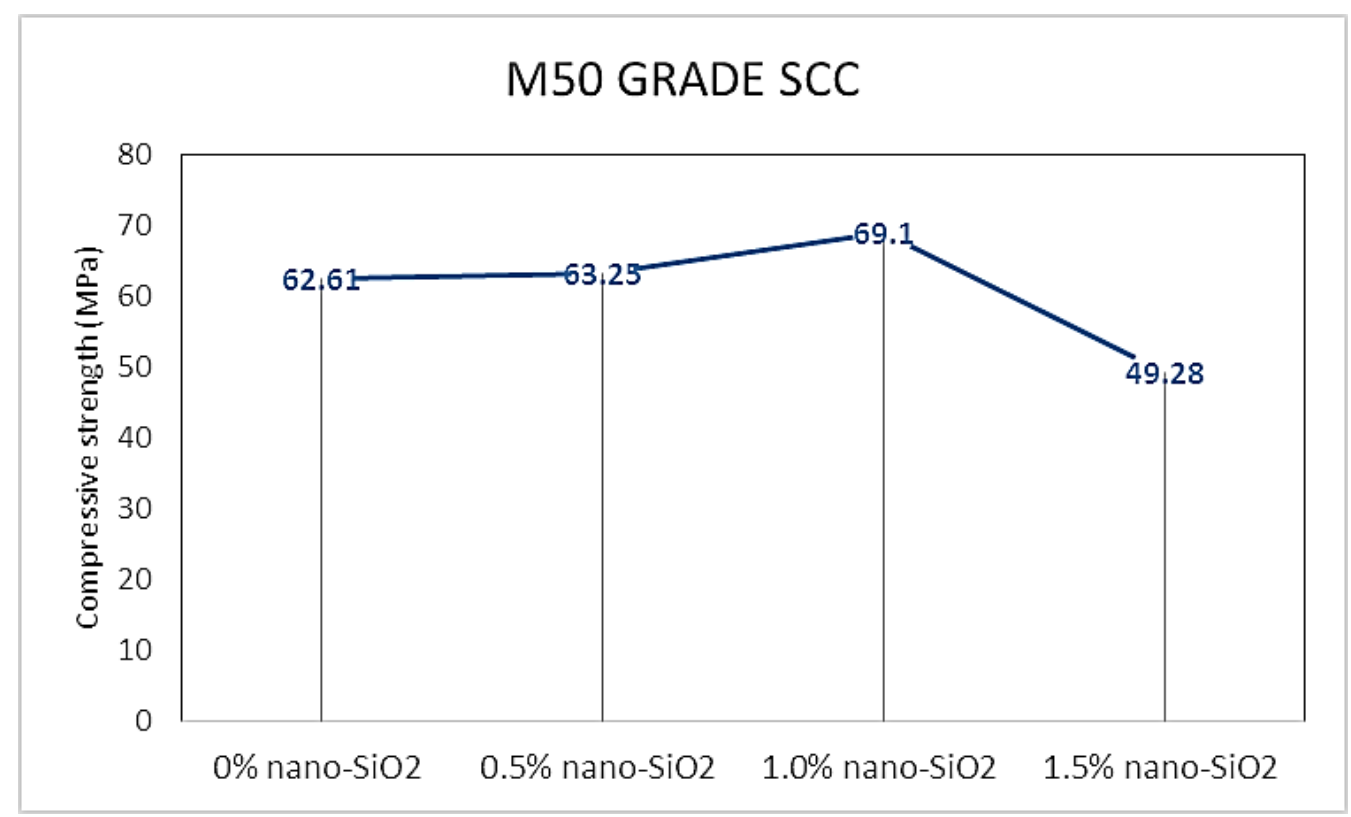

Fig. 4. Effect of nano- $\mathrm{SiO}_{2}$ on compressive strength

\section{Rebound hammer and Ultrasonic pulse velocity tests}

Fly ash has very low initial pozzolanic reactivity, but this activity considerably amplified after incorporating a small percentage of nano- $\mathrm{SiO}_{2}$. The use of fly ash creates a highly porous structure at early days of curing but inclusion of nano- $\mathrm{SiO}_{2}$ creates a more condensed microstructures, even during early ages of 1-3 days due to positive effect of nucleation of nano-silica. The following table presents the quality of M50 grade SCC made with $1.0 \%$ addition of nano- $\mathrm{SiO}_{2}$. based on combined rebound hammer and ultrasonic pulse velocity tests.

Table 6. Rebound hammer and Ultrasonic Pulse Velocity Tests Combined Rebound hammer and Ultrasonic Pulse Velocity values

\begin{tabular}{|c|c|c|c|c|c|c|c|c|}
\hline \multirow[b]{2}{*}{ 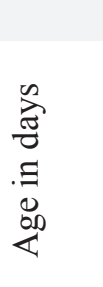 } & \multicolumn{4}{|c|}{ M50 grade reference SC } & \multicolumn{4}{|c|}{ M50 grade nano-silica based SCC } \\
\hline & 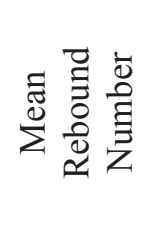 & 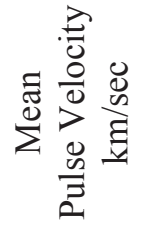 & 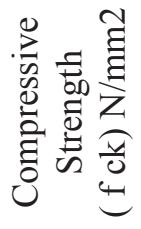 & 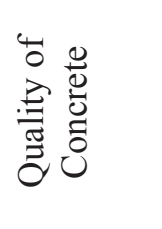 & 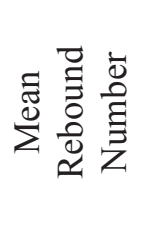 & 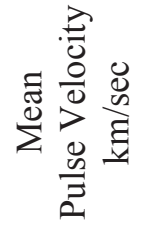 & 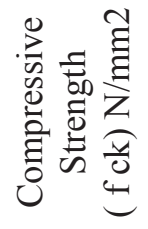 & 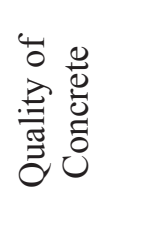 \\
\hline 28 & 41 & 4.89 & 62.61 & Excellent & 48 & 5.22 & 74.21 & Excellent \\
\hline 60 & 43 & 4.92 & 69.26 & Excellent & 51 & 5.36 & 82.92 & Excellent \\
\hline 90 & 44 & 4.99 & 73.59 & Excellent & 53 & 5.41 & 88.63 & Excellent \\
\hline
\end{tabular}

Rebound numbers obtained indicate the superior surface hardness than reference SCC and also the USPV measurements were greater than $4.5 \mathrm{~km} / \mathrm{sec}$ which denotes that nano-silica based SCC is classified as excellent concretes in terms of strength and durability point of view due to improved pore structure of concrete.

\section{Water absorbtion capacity and porosity}

Usage of nano-silica will accelerate the hydration process resulting in additional hydration products due reaction with portlandite formed during 1-3 days of 
curing. So the microstructure of concrete is densified due to both filler and pozzolanic effect particularly at the interface between aggregate and cement paste and between unhydrated cement grains and hydrated products forming a homogeneous and uniform structure. Distribution of pores are refined and their size is reduced drastically. The pozzolanic activity of nano-SiO2 is superior to that of micro-silica because nano-silica consumes more $\mathrm{CH}$ crystals reducing the size and orientation of $\mathrm{CH}$ crystals at the interface.

Figure below presents the water absorbtion capacity and porosity of M50 grade SCC made with $1.0 \%$ addition of nano- $\mathrm{SiO}_{2}$

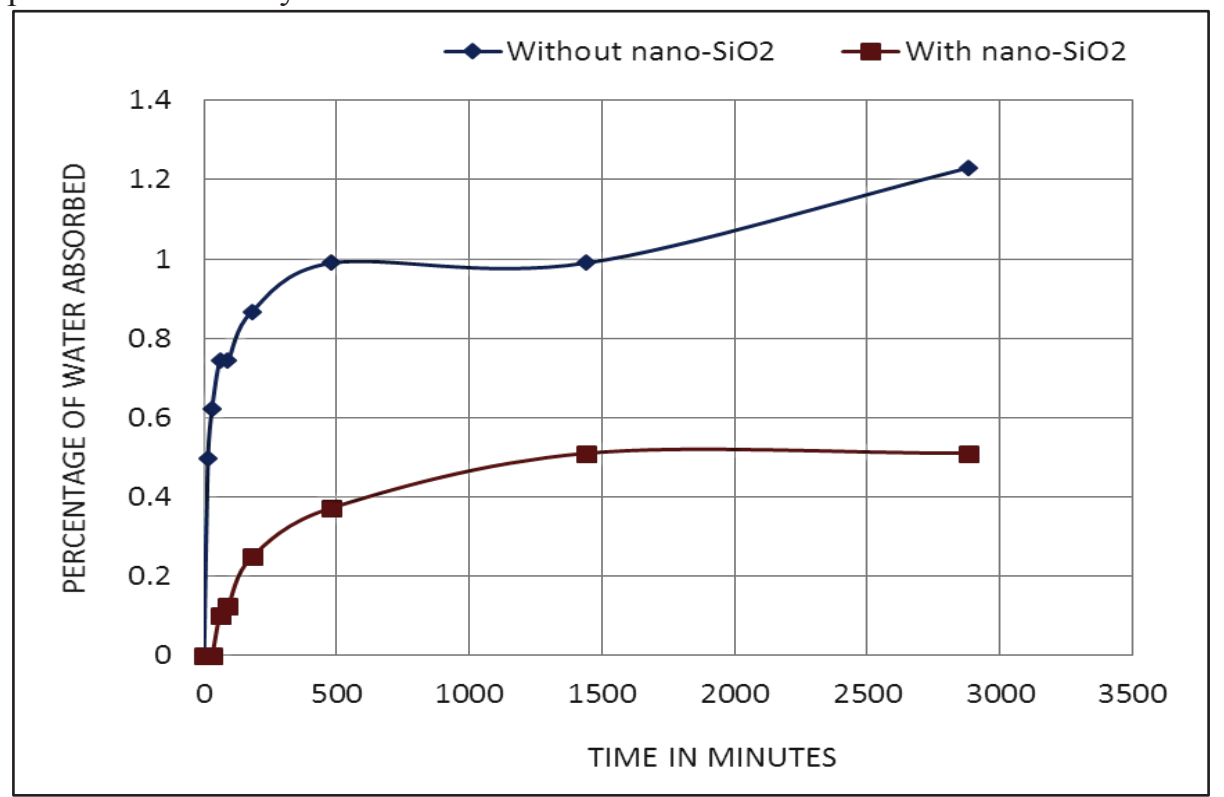

Fig. 5. Water absorbtion capacity and Porosity

Table 7. Permeation properties of $\mathrm{Nano}_{-} \mathrm{SiO}_{2}$ mixed $\mathrm{M} 50$ grade $\mathrm{SCC}$ mix Parameter $0 \%$ Nano- $\mathrm{SiO}_{2}$

$1.0 \%$ Nano- $\mathrm{SiO}_{2}$

\begin{tabular}{ccc}
\hline Water absorption capacity (\%) & 1.03 & 0.498 \\
Volume of permeable voids (\%) & 2.655 & 0.32 \\
Apparent porosity (\%) & 4.347 & 0.98
\end{tabular}

\section{Cost Involved}

Table 7 presents the costs involved in the development of $\mathrm{Nano}_{-} \mathrm{SiO}_{2}$ mixed M50 grade SCC.

Cost of Nano- $\mathrm{SiO}_{2}$ mixed M50 grade $\mathrm{SCC}$ mix

\begin{tabular}{ccccc} 
& M50 SCC & Cost & M50 SCC with 1\% & Cost \\
& Rs & Nano-SiO2 & Rs \\
\hline Cement $(\mathrm{kg} / \mathrm{m} 3)$ & 290 & 1885 & 210 & 1365 \\
fly ash $(\mathrm{kg} / \mathrm{m} 3)$ & 257 & 514 & 257 & 514 \\
Microsilica $(\mathrm{kg} / \mathrm{m} 3)$ & 27.4 & 602.8 & -- & - \\
Nanosilica $(\mathrm{kg} / \mathrm{m} 3)$ & -- & -- & 5.5 & 550 \\
$\begin{array}{c}\text { Fine aggregate } \\
\text { (kg/m3) }\end{array}$ & 891 & 1603.8 & 891 & 1603.8 \\
Coarse aggregate & 738 & 516.6 & 738 & 516.6 \\
$\quad(\mathrm{~kg} / \mathrm{m} 3)$ & 231.23 & 0 & 231.23 & 0 \\
Water $(\mathrm{L})$ & 3.4 & 136 & 11.8 & 473.6 \\
Superplasticizer $(\mathrm{L})$ & & $\mathbf{5 2 5 8 . 2 0}$ & $\begin{array}{c}\text { Cost of nano-SiO } \\
\text { mixed M50 grade }\end{array}$ & $\mathbf{5 1 8 3 . 0 0}$ \\
& Cost of M50 SCC & & SCC
\end{tabular}


Cement - Rs 6.5/kg; Fly ash- Rs 2/kg; Microsilica- Rs 22/kg; Nano-silica- Rs 100/kg; River Sand- Rs 1.8/kg; Coarse aggregate- Rs 0.70/kg; Water- Rs 0/kg; Superplasticizer- Rs 40/kg (Based on available market prices)

\section{Conclusions}

The following conclusions are established based on the test results obtained-

1. The optimum percentage of Nano-silica to be used in M50 grade SCC is determined to be $1 \%$ by weight of total powder.

2. Due to addition of nano-silica, the initial and final setting times of Nano-silica based cementitious materials are observed to be reduced.

3. Due to enhanced pore refinement due to Nanosilica, the compressive strength for $1 \%$ Nanosilica based SCC is nearly $30 \%$ more than that of plain SCC mix in 28 days.

4. The addition of Nano silica improves the hydrated structure of concrete by modifying the concrete pore structure by plugging the voids /or the nano pores within cement-sand matrix by nano-silica particles. The nano particles act as a filler to improve the density of concrete, which leads to the porosity of concrete reduced considerably.

5. Nano particles can not only act as an activator to accelerate cement hydration due to their high activity, but also makes the size of calcium hydroxide crystal smaller. Nano- $\mathrm{SiO}_{2}$ will absorb the calcium hydroxide crystals, and reduce the size and amount of the calcium hydroxide crystals, thus making the dense interfacial transition zone between the aggregates and binder paste matrix. This enhances the compressive strength due to rapid consumption of calcium hydroxide which formed during the hydration of cement especially at the early age due to high reactivity of nano-silica.

\section{References}

1. Said, A. M., Zeidan, M. S., Bassuoni, M. T., \& Tian, Y. (2012). Properties of concrete incorporating nano-silica. Construction and Building Materials, 36, 838-844.

2. Mondal, Paramita, Surendra P. Shah, Laurence D. Marks, and Juan J. Gaitero. "Comparative study of the effects of microsilica and nanosilica in concrete." Transportation Research Record 2141, no. 1 (2010): 6-9.

3. Nili, M., A. Ehsani, and K. Shabani. "Influence of nano-SiO2 and micro-silica on concrete performance." In Proceedings Second
International Conference on Sustainable Construction Materials and Technologies, pp. 1-5. 2010.

4. Du, Hongjian, Suhuan Du, and Xuemei Liu. "Durability performances of concrete with nanosilica." Construction and building materials 73 (2014): 705-712.

5. Quercia, G., and H. J. H. Brouwers. "Application of nano-silica (nS) in concrete mixtures." In 8th fib International $\mathrm{Ph}$. D. Symposium in Civil Engineering. Lyngby, vol. 20, no. 1, pp. 431-436. 2010.

6. Tummala Suresh Kumar, Kosaraju Satyanarayana, Materials Today: Proceeding, 26 (2), 3228-3233, (2020).

7. Maheswaran, S., B. Bhuvaneshwari, G. S. Palani, R. Nagesh, and S. Kalaiselvam. "An overview on the influence of nano silica in concrete and a research initiative." Research Journal of Recent Sciences, ISSN2277 (2013): 2502. 